\title{
Mild hemophilia B
}

INSERM

\section{Source}

INSERM. (1999). Orphanet: an online rare disease and orphan drug data base. Mild hemophilia B. ORPHA:169799

Mild hemophilia B is a form of hemophilia B (see this term) characterized by a small deficiency of factor IX leading to abnormal bleeding as a result of minor injuries, or following surgery or tooth extraction. 